\title{
A FORMAÇÃO INICIAL DE PROFESSORES NO CONTEXTO DA DIVULGAÇÃO DE CIÊNCIAS EM UM MUSEU DE HISTÓRIA NATURAL UNIVERSITÁRIO
}

\author{
José Sebastião Andrada de Melo ${ }^{1}$ \\ Lorrana Nascimento Ferreira ${ }^{2}$ \\ Antonio Fernandes Nascimento Junior ${ }^{3}$
}

\section{RESUMO}

Este trabalho se refere às ações de divulgação científica e formação de professores realizadas no Museu de História Natural (MHN) da Universidade Federal de Lavras (UFLA). A atividade investigada trata de uma proposta didática para o ensino de Química que explora o acervo deste museu. Os objetivos deste trabalho foram desenvolver uma prática didática diferenciada dentro de um MSH para promover o ensino e a divulgação de conteúdos da Química, além de investigar qual contribuição formativa foi dada aos licenciandos envolvidos, que cumpriram parte de seus estágios supervisionados nos eventos realizados neste espaço não formal de educação. Como resultado, os participantes desta atividade desenvolveram uma prática pedagógica diferenciada intitulada "Detetives no museu - Investigando a questão: de que é feito nosso planeta?" Nesse sentido, houve a confirmação da hipótese quanto às contribuições à formação inicial de professores, visto que a participação dos licenciandos no planejamento e na execução de atividades educacionais em um museu de ciências possibilitou aos graduandos a oportunidade de complementarem sua formação por exploraram um espaço não formal de ensino. Chama-se atenção para um fato interessante que pode ser constatado neste e em outros relatos. As experiências de formação de professores em espaços não formais de educação, tais como museus, centro de ciências e centros culturais, apesar de serem raras em nosso país, são ricas e vêm contribuindo para a formação inicial de professores.

Palavras Chave: Formação inicial de professores; Espaços não formais de educação; Divulgação em ciências.

\section{INITIAL TEACHER EDUCATION IN THE CONTEXT OF DISCLOSURE OF SCIENCE IN A MUSEUM OF NATURAL HISTORY UNIVERSITY}

\author{
ABSTRACT \\ ${ }^{1}$ Licenciado em Química - Universidade Federal de Lavras - jsamelo@proec.ufla.br \\ ${ }^{2}$ Graduação - Bolsista de Iniciação à Docência - PIBID, Universidade Federal de Lavras- \\ lolorrana@gmail.com \\ ${ }^{3}$ Professor Adjunto, Universidade Federal de Lavras -toni_nascimento@yahoo.com.br
}


This work refers to the actions of scientific dissemination and training of teachers held at the Museum of Natural History (MNH) of the Federal University of Lavras (UFLA). The activity under investigation is a didactic proposal for teaching chemistry that explores the collection of this museum. The objectives of this study were to develop a differentiated teaching practice within a MSH to promote the teaching and dissemination of the contents of Chemistry, besides investigating which formative contribution was given to undergraduates involved, who spent part of their supervised training events held in this space non-formal education. As a result, participants of this activity developed a differentiated pedagogical practice entitled "Detectives in the museum - Investigating the question : what is it made our planet" Accordingly, there was confirmation of the hypothesis concerning contributions to initial teacher training, since the participation of undergraduates in the planning and implementation of educational activities in a science museum allowed the graduate students the opportunity to complement their training explored by a non-formal teaching space. Called attention to an interesting fact that can be seen in this and other reports. The experiences of teacher education in non-formal educational spaces such as museums science centers and cultural centers, although they are rare in our country, are rich and have contributed to the initial training of teachers.

KEY-WORDS: Initial teacher training; Non-formal educational spaces; Dissemination of science .

\title{
EDUCACIÓN INICIAL DEL PROFESORADO EN EL CONTEXTO DE LA DIVULGACIÓN DE LA CIENCIA EN UN MUSEO DE HISTORIA NATURAL DE LA UNIVERSIDAD
}

\begin{abstract}
RESUMEN
Este trabajo se refiere a las acciones de divulgación científica y la formación de los maestros en el Museo de Historia Natural (MNH), de la Universidad Federal de Lavras (UFLA) . La actividad objeto de la investigación es una propuesta didáctica para la enseñanza de la química que explora la colección de este museo. Los objetivos de este estudio fueron desarrollar una práctica de enseñanza diferenciada dentro de un MSH para promover la enseñanza y la difusión de los contenidos de la Química, además de la investigación de la que se le dio contribución formativa para los estudiantes universitarios que participan, que pasó parte de sus actividades de formación supervisadas celebradas en este espacio la educación no formal. Como resultado, los participantes de esta actividad desarrollaron una práctica pedagógica diferenciada titulado " Detectives en el museo - La investigación de la pregunta: ¿ de qué está hecho nuestro planeta " En consecuencia, no había confirmación de la hipótesis, sobre las contribuciones a la formación inicial del profesorado , ya que el la participación de los estudiantes en la planificación y ejecución de las actividades educativas en un museo de la ciencia permitió a los estudiantes de posgrado la oportunidad de complementar su formación explorado por un espacio de enseñanza no formal . Llamó la atención sobre un hecho interesante que se puede ver en este y otros informes. Las experiencias de la formación del profesorado en los espacios educativos no formales, tales como museos, centros científicos y centros culturales, aunque son poco frecuentes en nuestro país, son ricos y han contribuido a la formación inicial de los profesores.
\end{abstract}

PALABRAS-CLAVE: La formación inicial del profesorado; Espacios educativos no formales ; La difusión de la ciencia . 


\section{INTRODUÇÃO}

As práticas pedagógicas de ensino e divulgação das ciências naturais visando estimular o aprendizado e a compreensão do estudante sobre os aspectos sociais e econômicos da sociedade vem se tornando ao longo dos últimos anos uma prioridade nas propostas curriculares e nas políticas públicas educacionais.

A popularização da ciência ou divulgação científica pode estar orientada para diferentes objetivos, o enfoque deste trabalho, é o caráter educacional e cívico ou seja, a ampliação do conhecimento e da compreensão do público leigo a respeito do processo científico, e o desenvolvimento de uma opinião pública informada sobre os impactos do desenvolvimento científico e tecnológico sobre a sociedade. (ALBAGLI, 1996).

Os frutos do desenvolvimento da ciência e da tecnologia, bem como suas consequências ambientais e sociais, estão cada vez mais em pauta nos debates contemporâneos, o que nos convida a refletir sobre os possíveis espaços que promovam uma educação contextualizada que proporcione a divulgação científica. Sendo assim, as necessidades não atendidas pela escola, espaço formal de educação, seriam complementadas ou supridas por atividades oferecidas em outras instituições ou em outros espaços considerados não formais. Estes locais, classificados na literatura nacional por Gohn (2008) como espaços não formais de educação são os centros culturais, os museus de artes, as bibliotecas, os parques ecológicos, zoológicos, centros e museus de ciências, entre outros. Suas ações independem da imposição de programas curriculares pré-estabelecidos, podendo, assim, atuar de forma mais livre, acompanhando e tratando grandes questões atuais, tendo o dinamismo e o pluralismo como características implícitas em suas práticas educativas, além de promoverem a construção do conhecimento acerca de conteúdos de ciências naturais.

Destacando a importância destes espaços não formais de educação e tendo em vista a necessidade da existência de um centro de ciências no sul de Minas Gerais, um grupo de pesquisadores, professores e alunos de graduação da Universidade Federal de Lavras (UFLA) desenvolveram um projeto de extensão 
universitária, denominado Projeto Ciência em Ação. Sua proposta esteve atrelada à elaboração e execução de atividades dinâmicas e de diferentes práticas culturais com intuito de aumentar a democratização e popularização da Ciência e Tecnologia. O projeto foi desenvolvido em torno do Museu de História Natural (MHN) desta instituição que foi utilizado para a promoção de um grande repertório de práticas científico-culturais. Estas eram repletas de atividades interativas que visavam divulgar o conhecimento científico para a população em geral. Além de possibilitar aos alunos dos cursos das licenciaturas da universidade puderam realizar uma pequena parte da carga horária destinada aos estágios supervisionados nas escolas, desenvolvendo atividades e práticas de ensino e divulgação em ciências no MHN com os alunos das turmas os quais já acompanhavam, ampliando desta maneira sua formação como educador.

Este é o aspecto que será enfatizado neste trabalho, a possibilidade de participação e realização de estágios para alunos dos cursos de licenciaturas em cenários educacionais diferentes do escolar. São vários os ambientes entendidos como "espaços não formais de educação" que podem contribuir para a educação, cultura e veiculação de informação para um público amplo e diversificado e que, segundo Jacobucci (2010) carecem de profissionais qualificados. Nesse sentido, estre trabalho proporciona o diálogo entre os espaços não formais de educação e a popularização da ciência de modo a contribuir com à formação inicial dos licenciandos e licenciandas participantes do projeto. Além de contribuírem com a formação destes educadores de uma maneira diferenciada, já que são poucas as instituições no Brasil que oferecem esse tipo de possibilidade de vivência (MELO, 2009), e de promover um projeto de Educação Ambiental com escolas públicas do ensino básico do munícipio de Lavras e para a sociedade em geral que frequenta o espaço do MHN da UFLA.

\section{DESENVOLVIMENTO}

As atividades realizadas pelo Projeto Ciência em Ação iniciaram em Março de 2013, e foram elaboradas por alunos do curso das Licenciaturas em Química, Física e Biologia, que no momento estagiavam no museu. 
Os procedimentos investigativos consistiram na realização de entrevistas individuais semi-estruturadas com os licenciandos e licenciandas participantes dos estágios envolvidos nas atividades do Projeto Ciência em Ação após terem terminado a sua participação no projeto, e na consulta de seus relatórios de prática.

O Projeto Ciência em Ação contou com duas dinâmicas ocorrendo em locais diferentes, uma no planetário do MHN e outra nos setores de zoologia e mineralogia deste museu. Para o ensino de alguns conceitos de física e de alguns fundamentos de astronomia foi utilizado o planetário, onde os visitantes participaram de uma simulação áudio - visual de uma viagem pelo universo. Após a sessão houve um debate relacionado aos assuntos abordados. Em relação às ações desenvolvidas nos setores do MHN realizou-se duas oficinas temáticas: uma para o ensino de Biologia e outra voltada para o ensino de Química, as quais ocorreram concomitantemente após a divisão do público participante em dois grupos.

Uma visita guiada pelo acervo de zoologia do $\mathrm{MHN}$ foi a dinâmica utilizada para o ensino de alguns aspectos de Biologia.

A atividade desenvolvida para o ensino de Química recebeu a denominação "Detetives no Museu - Investigando a questão: de que é feito nosso planeta?", e esta será analisada nas próximas seções deste trabalho. Procurou-se com ela explorar todo potencial de ensino do acervo de mineralogia do MHN.

\section{O planejamento da atividade}

A classificação adotada no MHN da UFLA pretende descrever, em suas vitrines, a formação do planeta Terra, sua geologia e a biologia dos seres pertencentes aos cinco reinos da natureza. Os alunos envolvidos com o projeto foram orientados a elaborarem práticas pedagógicas de biologia e química que explorassem o acervo do MHN. Ao início da prática, os alunos constataram que o museu tem um grande acervo de espécies minerais, sendo cerca de $25 \%$ de sua exposição permanente é voltada à mineralogia. Devido esse fato, foi sugerido que a temática central a ser trabalhada fosse a constituição do planeta Terra. Esta atividade receberia a seguinte denominação: “De que é feito nosso planeta?" e 
exploraria o grande acervo de espécies minerais do $\mathrm{MHN}$, aliado ao ensino de Química. O principal objetivo dos licenciandos e licenciandas era incitar a curiosidade do público do MHN da UFLA pelo tema e provocar reflexões sobre os conteúdos químicos e ambientais, tanto conceituais quanto os relacionados a atitudes e valores. Para contribuir para o planejamento do ensino dentro do museu os alunos se basearam nos Conteúdos Básicos Comuns (CBC) do estado de Minas Gerais (MINAS GERAIS, 2006), que são utilizados em todas as escolas públicas de nível fundamental e médio deste estado. Quanto aos conteúdos relacionados ao tema escolhido, "De que é feito nosso planeta?", escolheu-se os conteúdos que estão no Eixo Temático I do CBC, que versa sobre materiais. Assim sendo, as habilidades relacionadas ao conhecimento químico trabalhadas com o público foi o reconhecimento, a origem e a ocorrência dos materiais.

Quanto à relevância dos conteúdos, é um consenso entre professores e educadores de ciências que os estudantes apresentam dificuldades em estabelecer relações entre os conteúdos científicos e situações da vida cotidiana (FOUREZ, 2003; CHASSOT, 2006; VASCONCELOS et al., 2007). Uma das formas de enfrentar tal situação, de acordo com o CBC, é a organização dos conteúdos em torno do tema vinculado à vivência dos estudantes. Atingiu-se essa dimensão de relevância do tema trabalhado ao tratar sobre a constituição do ambiente terrestre, da atmosfera, do solo, do planeta onde todos os seres vivos que conhecemos vivem, dando ênfase a aspectos relacionados à preservação ambiental, uso sustentável de matérias-primas, reaproveitamento e reciclagem. Também foi dada ênfase aos aspectos referentes as atividades humanas e industriais comuns à região do interior de Minas Gerais, tais como a extração de recursos minerais e seus impactos ambientais como degradação e poluição do meio ambiente.

Durante a atividade, foi importante, o reconhecer dos licenciandos e licenciandas em formação que características da educação tradicional de ensino, como a fragmentação dos saberes, não devia ser reproduzida também em um espaço não formal de educação.

A abordagem de certos conteúdos, feita de modo recursivo, como, por exemplo, o uso do recurso da experimentação para determinar a quantidade de $\mathrm{CO} 2$ presente em amostras de ar coletados em áreas onde há poluição e onde não há; o 
uso do acervo do MHN para mostrar os minerais mais presentes no planeta Terra ou para demonstrar o arranjo cristalino das estruturas moleculares nas espécies minerais permitiu o tratamento de conteúdos em diferentes níveis de complexidade e em diferentes contextos ao longo do desenvolvimento da atividade.

\section{O envolvimento dos licenciandos}

A atuação dos licenciandos e licenciandas durante os dias de visita dos alunos da educação básica ao MHN foi planejada de forma que o estudante em formação inicial seria o mediador entre as exposições do museu e seus visitantes, teriam que despertar a curiosidade entre o público. Os licenciandos e licenciandas atuando como mediadores, teriam como objetivo principal incitar a curiosidade do público pelo tema e provocar reflexões sobre os conteúdos químicos e ambientais, tanto conceituais quanto os relacionados a atitudes e valores.

Para a abordagem da questão "De que é feito nosso planeta?" dividiu-se a temática em dois tópicos chamados "principais" e esses em seus respectivos subtópicos, conforme a Tabela 1.

Tabela 1. Divisão da temática abordada.

\begin{tabular}{|c|c|}
\hline Tópico Principal & Subtópicos \\
\hline 1) A estrutura do planeta Terra & $\begin{array}{c}\text { Litosfera } \\
\text { Hidrosfera } \\
\text { Atmosfera }\end{array}$ \\
\hline 2) Os minerais do planeta Terra & $\begin{array}{c}\text { Rochas Magmáticas } \\
\text { Rochas Sedimentares } \\
\text { Rochas Metamórficas }\end{array}$ \\
\hline
\end{tabular}

A equipe de execução dessa atividade consistiu em dois grupos de mediadores, cada grupo formado por quatro alunos dos cursos de Licenciatura da UFLA, que se revezaram durante os dias de visita do público escolar ao MHN. Na Tabela 2 está o quadro esquemático final das atividades que foram desenvolvidas por cada mediador na execução desta prática de ensino no MHN. O público alvo convidado a participar dos eventos do Projeto Ciência em Ação, no caso desta prática de ensino, foram alunos dos oitavos e nonos anos do Ensino Fundamental e 
primeiro ano do Ensino Médio, de escolas da rede pública de educação da cidade de Lavras/MG.

Tabela 2. Quadro esquemático das atividades desenvolvidas pelos licenciados no MHN.

\begin{tabular}{|l|l|}
\hline Licenciando & \multicolumn{1}{|c|}{ Atividade desenvolvida } \\
\hline Mediador A & $\begin{array}{l}\text { Apresentação de uma breve apresentação oral abordando o "tópico principal 1" com } \\
\text { uso de recurso audiovisual, projeção de um pequeno vídeo contendo belas imagens de } \\
\text { diferentes regiões do planeta Terra, ressaltando a dinâmica natural existente nos } \\
\text { quatro grandes sistemas de nosso planeta, atmosfera, hidrosfera, litosfera e biosfera. }\end{array}$ \\
\hline Mediador B & $\begin{array}{l}\text { Apresentação do "tópico principal 2": Conceito de mineral. Apresentação de } \\
\text { propriedades químicas e características físicas das seguintes espécies minerais: } \\
\text { Quartzo, Magnetita, Argila, Turmalina, Grafite, Pirita, Petróleo. }\end{array}$ \\
\hline Mediador C & $\begin{array}{l}\text { Apresentação do "tópico principal 2": Definição de rochas magmáticas, sedimentares e } \\
\text { metamórficas. Apresentação de propriedades químicas e características físicas das } \\
\text { seguintes espécies minerais: Granito Gabro, Calcário, Apatita, Calcita, Barita, Fluorita, } \\
\text { Quartzito, Gnaisse. }\end{array}$ \\
\hline Mediador D & $\begin{array}{l}\text { Exibição um segundo vídeo com imagens de diferentes regiões do planeta, imagens } \\
\text { contrastantes com a do primeiro vídeo. Incitar e provocar um debate no fim das } \\
\text { atividades. }\end{array}$ \\
\hline
\end{tabular}

Para abordar o "tópico principal 1" apresentou-se uma breve palestra. Nela foram discutidas as definições de cada estrutura do planeta Terra e suas respectivas composições químicas em termos de porcentagem. O público foi instigado a refletir e a procurar respostas, como detetives, para as seguintes questões: qual a composição da atmosfera e por que ela é importante para a vida? Como se distribui a água em nosso planeta? Como pode haver "falta" de água em nosso planeta, já que é uma substância tão abundante? De que é feito o solo? Como ele é formado?

Durante esta primeira fala também foram realizados alguns experimentos simples, um destes feito da seguinte maneira: colocou-se certa quantidade de terra de jardim em um béquer grande com $1 \mathrm{~L}$ de água. Este foi deixado em repouso durante toda a apresentação do seminário, cerca de 20 minutos. Após esse tempo, o público foi convidado a voltar sua atenção para o que havia acontecido com a terra de jardim dentro do béquer e como os materiais presentes na mistura de terra se 
separaram dentro dele. Após a análise do que havia acontecido, e com as sugestões dadas pelo mediador, formulou-se conjuntamente, uma explicação próxima da seguinte:

\begin{abstract}
"- Após algum tempo em repouso foi possível perceber a sedimentação de materiais mais densos que a água, enquanto outros flutuaram. A parte mais densa é formada por grãos de tamanhos variados constituídos principalmente de Silício e Oxigênio, na forma de silicatos. A turvação da água foi provocada pelas argilas, materiais também formados, principalmente, por silicatos. Os materiais menos densos que a água, que podem ser observados flutuando na superfície, são chamados genericamente de matéria orgânica ou húmus, que é constituída por restos de seres vivos (animais e vegetais) em decomposição" (Mediador A, durante a execução da atividade "Detetives no Museu")
\end{abstract}

Esse experimento ficou sendo o elo entre os tópicos 1 e 2. Assim, após sua realização, o público foi convidado a assistir um vídeo. Tratava-se de um pequeno vídeo editado a partir de imagens do documentário "Koyaanisqatsi" (1982), onde belas cenas de nosso planeta, do ambiente natural sem a presença ou interferência humana, foram mostradas. Logo após, os alunos partiriam para a busca dos minerais mais presentes no planeta pelo acervo do museu.

De um dos relatórios finais dos estagiários analisados, destaca-se a seguinte passagem:

\begin{abstract}
"Vale ressaltar que muitas dúvidas eram apresentadas pelo público, e uma constatação interessante é que a grande maioria delas referia-se à formação do solo. Para explicar tais dúvidas, quando pertinente, um aprofundamento era dado ao assunto. A formação do solo então fora explicada exaltando a ação dos agentes físicos, químicos e biológicos, ou seja, o processo chamado de intemperismo. Assim, trabalhava-se com o modelo mais comumente aceito para explicar esse processo dividindo-o em várias partes, e explicando cada uma delas, a saber: (a) $A$ ação das variações de temperatura, durante o dia. $O$ calor do sol provoca aquecimento e pequenas dilatações nas rochas e a noite, a queda de temperatura ocasiona contração destas. Explicava-se essas oscilações de temperatura provocando rachaduras em pequenas amostras de minerais; (b) $A$ ação dos ventos e das águas de chuvas que também podem causar a fragmentação das rochas. Imagens desse efeito eram exibidas no vídeo apresentado; (c) A ocorrência de reações químicas entre substâncias das rochas e as águas de chuva. Explicava-se a pequena acidez das águas de chuvas devido a reações com dióxido de carbono e (d) a atividade de bactérias e fungos que também participam da formação do solo, explicavase que posteriormente participam do processo organismos mais complexos como os liquens, algas e musgos e estes juntamente com outras complexas interações entre os fenômenos químicos, físicos e biológicos, preparam o caminho para a instalação de vegetais superiores e seres vivos que se utilizam da água do solo e de nutrientes contendo fósforo, nitrogênio e potássio, principalmente. Sempre procurava-se fazer a relação com os
\end{abstract}


conteúdos que também eram trabalhados na atividade do projeto que se propunha ao ensino de Biologia. O intuito era fazer o público compreender que a composição geral de um solo possui quatro componentes fundamentais, que se apresentam em variadas proporções: areia, calcário, argila e húmus. Sendo que, a composição da areia, do calcário, da argila e do húmus, eram mais questões de investigação para o público".

Neste trecho o estagiário mostrou como foi feita a abordagem sobre um dos temas presentes nesta prática de ensino, evidenciando neste momento sua vivência na prática como educador. Essa vivência se deu de tal forma que o estagiário tomou parte na atividade de forma sistemática e objetiva, reconhecendo o objetivo da prática, aquilo que é definido por Ghisolfi da Silva e Schnetzler (2008) como ensinar e aprender, de modo intencional, não casuístico, exercendo seu papel nesse processo de ensino e aprendizagem.

Para abordar o "tópico principal 2" o público foi guiado pelo acervo de minerais do Museu. Deu-se ênfase à aplicação e importância das espécies minerais do acervo do MHN. Explicou-se também o que foi observado no experimento com a terra do jardim e, quando possível, no caso do público do ensino médio, exemplificou-se os arranjos moleculares e as diferentes estruturas cristalinas das espécies minerais. Em um local próximo às coleções, foi apresentado outro vídeo breve, com montagens de fotos que retratavam problemas sócio-econômicoambientais que o meio ambiente, o homem e a Terra vêm enfrentando. O objetivo de mostrar esse vídeo foi de provocar um debate sobre questões referentes à preservação ambiental no fim da atividade.

Um roteiro com questões foi entregue ao público. A finalidade deste instrumento foi apresentar algumas questões para que os visitantes, que atuando como detetives no museu, buscaram respostas. Assim, antes de se iniciar as atividades este roteiro com questões era lido, apresentado, assim como a meta a ser atingida, a de encontrar respostas para as questões. Todos os presentes procuraram responder as questões do roteiro, sendo que nenhum questionário foi entregue com mais do que três questões sem serem respondidas, o que leva a suspeita de que um processo de ensino-aprendizagem estava sendo firmado.

A seguir são apresentadas algumas considerações dos licenciandos e licenciandas envolvidos com a atividade nas quais se percebe que todos julgaram 
satisfatórias suas participações, e como tais contribuíram para suas formações como educadores de ciências.

“- O estágio realizado representou uma importante etapa de minha formação profissional. Certamente a participação nessa atividade superou minhas expectativas. Imensas contribuições foram dadas a mim, como estudante de licenciatura, ressalto a prática e a vivência no exercício de minha futura profissão de educador em química." (Mediador D, em entrevista)

"- O estágio no museu fez com que descobrisse algumas coisas fundamentais. Aprendi como agir em situações adversas, contorná-las, além de conhecer uma nova possibilidade de prática educacional, a prática nos ambientes não formais de educação. Acho que adquiri certas habilidades, como por exemplo, a de saber planejar práticas de ensino. Pude alcançar certos objetivos como o de aprender a lidar com o ensino de ciências lançando mão de diferentes ferramentas e recursos, o que servirá de orientação para uma futura atuação profissional, até mesmo dentro do ambiente escolar". (Mediador B, em entrevista).

"- As atividades executadas no Projeto Ciência em Ação contribuíram bastante para minha formação acadêmica enquanto aluna de um curso de licenciatura, principalmente com a oportunidade de trabalhar diretamente com os alunos, em um espaço não-formal de ensino, com abertura para planejamento e execução das atividades. Esse contato direto, muitas vezes não liberados em estágios nas escolas pela direção, professores ou orientadores, foi uma grande oportunidade de vivência e prática didática." (Mediador $\mathrm{C}$, em entrevista)

Um dos estagiários fez um comentário interessante em seu relatório de estágio:

\footnotetext{
"Em um sentido geral, o trabalho coletivo entre os vários indivíduos que fazem parte do processo de ensino-aprendizagem, infelizmente, não faz parte de nossa cultura escolar e precisa ser estimulado, e foi isso que procuramos fazer, e aconteceu sempre no museu". (Consideração final presente no relatório de estágio do Mediador A).
}

Ele identificou um aspecto, o trabalho coletivo, presente na atividade proporcionada pelo museu e geralmente ausente no espaço formal de educação, na escola. Conforme o relato do Mediador A, nas atividades desenvolvidas no $\mathrm{MHN}$, sempre trabalhou-se com um grupo de indivíduos, sendo assim possível concluir que o diálogo entre os envolvidos foi, juntamente com o acervo em exposição, o principal instrumento pedagógico, evidenciando o papel essencial do licenciando, atuando como um educador, no decorrer da atividade, ou seja, novamente nota-se o estagiário vivenciando ativamente a prática docente.

Outro estagiário relatou algumas dificuldades encontradas: 
"A maior dificuldade foi na avaliação das atividades, já que não conseguimos definir uma metodologia de avaliação sistematizada que integrasse todos os aspectos importantes a serem avaliados em um projeto como este. As percepções acerca do interesse dos alunos com relação às atividades puderam ser bem vivenciadas e sentidas, mas mostrou-se difícil avaliar o aprendizado alcançando". (Dificuldade descrita no relatório final de estágio do Mediador C).

Essa dificuldade em avaliar o real aprendizado dado ao visitante, e percebida por este estagiário, sempre esteve presente quando se reporta aos processos de ensino aprendizagem presentes em ambientes não formais de educação. Robert Semper, diretor do Exploratorium Museam de São Francisco, EUA, também descreve tal fato com muita propriedade:

\begin{abstract}
"Educadores, cientistas e "designers" que trabalham em centros de ciências sentem, instintivamente, que uma educação significativa está ocorrendo e muitos educadores têm um impressionante repertório de relatos de casos que evidenciam que ela de fato ocorre. Mas a exata natureza do processo de aprendizagem em centros de ciências não é inteiramente compreendida". (SEMPER, 1990, apud GASPAR,1993,p.43).
\end{abstract}

Outros discorreram sobre as dificuldades ultrapassadas.

\begin{abstract}
"Considero a maior dificuldade na realização de atividades como esta a questão de se apresentar algo que realmente prenda a atenção da maioria dos visitantes. Isso só acontecerá com um bom planejamento, uma apresentação com bases concretas e simpatia, fazendo assim com que aqueles momentos sejam realmente atraentes ao público. Percebi que, de certa forma, conseguimos ultrapassar essa barreira, o que foi perceptível no grau de envolvimento que os mesmos tiveram nas apresentações e discussões". (Percepção descrita no relatório final do Mediador B).
\end{abstract}

\title{
CONCLUSÃO
}

A realização de estágios nas atividades de ensino e divulgação em ciências em um espaço não formal possibilitou a licenciandos e licenciandas a oportunidade de complementarem sua formação como educadores de uma maneira diferenciada, já que tradicionalmente os estágios supervisionados dos cursos de licenciatura no Brasil estão restritos somente à observação de aulas em ambientes escolares.

Este trabalho foi realizado com o intuito de compreender as contribuições das ações de formação pretendidas, no sentido de levar os sujeitos de uma dada posição a outra. O desenvolvimento das atividades do Projeto - Ciência em Ação 
objetivaram contribuições para a alfabetização científica de jovens estudantes da educação básica e contribuições à formação inicial de professores.

Com este trabalho o fato constatado foi a possibilidade da mudança do lugar social do professor em formação, da sala de aula em uma escola, para a prática de ensino em museus de ciências. Essa mudança ocorreu quando os professores em formação, atuaram no planejamento e execução de atividades ao invés de apenas estagiarem de maneira meramente "passiva" nas escolas. Ao todo, em aproximadamente 18 meses, 47 licenciandos estiveram envolvidos com o Projeto Ciência em Ação, sendo que 29 cumpriram parte de suas cargas horárias de estágio supervisionado obrigatório em atividades no MHN. Destes, 8 participaram da prática "Detetives no museu - Investigando a questão: de que é feito nosso planeta?" relatada neste trabalho.

\section{REFERÊNCIAS}

ARROIO, A.; HONÓRIO K. M.; WEBER, k. C.; HOMEM-DE-MELO, P.; GAMBARDELLA, M. T. do P. e SILVA, A. B. F. da. O show da Química: Motivando o interesse Científico. Química Nova, v.29, n.1, p.173-178, 2006.

CHASSOT. A. Alfabetização científica: Questões e desafios para a educação. 4.ed. ljuí: Editora Unijuí, 2006.

CHIZZOTTI, A. A pesquisa em ciências humanas e sociais. São Paulo. Cortez, 1991.

FOUREZ, G. Crise no Ensino de Ciências? Investigações em Ensino de Ciências, v.8, n.2, 2003.

GASPAR, A. Museus e Centros de Ciências: Conceituação e Proposta de um Referencial Teórico. 1993. 143 f. Tese (Doutorado em Didática). Faculdade de Educação, Universidade de São Paulo, São Paulo, 1993.

GHISOLFI da SILVA, R. M.; SCHNETZLER, R. P. Concepções e ações de formadores de professores de Química sobre o estágio supervisionado: propostas brasileiras e portuguesas. Química. Nova, v. 31, n. 8, p. 2174-2183, 2008.

GIORDAN, M. O papel da experimentação no ensino de ciências. Química nova na escola, n.10, p. 43-49, nov. 1999.

GOHN, M. da G. Educação Não-Formal. In. Educação Não-Formal e Cultura Política: Impactos sobre o associativismo do terceiro setor. 4. ed. São Paulo: Cortez, 2008. p. 90-111. 
JACOBUCCI, D. C. F. Professores em espaços não-formais de educação: acesso ao conhecimento científico e formação continuada. In: Ana Maria de Oliveira CUNHA, A. M. de O.; DALBEN, A.; DINIZ, J.; LEAL, L. SANTOS L. Convergências e tensões no campo da formação e do trabalho docente. $1^{1}$ Ed. Belo Horizonte: Editora Autentica, 2010. p. 426-446..

MELO, J. S. A. de. Atividades de divulgação e ensino de ciências em um museu de história natural: Contribuições para a alfabetização científica de jovens e para a formação inicial de professores. 2009. 98 f. Monografia de Conclusão de Curso (Graduação em Licenciatura em Química). Departamento de Química, Universidade Federal de Lavras, Lavras, 2009. p. 45-60.

MINAS GERAIS (Estado). Conteúdos Básicos Comuns de Química: CBC Química. Belo Horizinte: Secretaria de Estado de Educação, 2006.

ROQUEPLO,P. La partage du savior. [S.I]: Éditions du Sueli. 1974

SEMPER, R. J. Science Museums as Enviroment for Learning. Physics Today, 1990

VASCONCELOS, C.; LOPES, B.; COSTA, L.; MARQUES, L. CARRASQUINHO, S. Estado da arte na resolução de problemas em Educação em ciências. Revista Eletronica de Enseñanza de las Ciencias, v. 6, n.2, p. 235-245. 2007.

ALBAGLI, S. Divulgação científica: Informação para a cidadania. Cadernos de Informação. Brasília, v.25,n.3, p 396-404. 1996. 